\title{
ACE DD polymorphism in severe COVID-19
}

\author{
Anna Annunziata ${ }^{1 *}$, Antonietta Coppola ${ }^{1}$, Maurizia Lanza ${ }^{1}$, Francecsa Simioli ${ }^{1}$, Pasquale Imitazione ${ }^{1}$, Nicola Pepe ${ }^{2}$, Valeria Maddaloni $^{2}$, \\ Luigi Atripaldi ${ }^{2}$ and Giuseppe Fiorentino ${ }^{1}$ \\ ${ }^{1}$ Department of Respiratory Pathophysiology Monaldi - Cotugno Hospital, Naples, Italy \\ ${ }^{2}$ Department of Molecular genomics lab, Chemical biochemistry Unit, Monaldi Hospital, Italy
}

\begin{abstract}
The insertion/deletion polymorphism of the angiotensin converting enzyme (ACE) gene, previously described in association with adult respiratory distress syndrome, may play a key role in lung injury in patients with SARS-COV2. In this paper we describe 26 patients with severe respiratory failure related to COVID-19 pneumonia that underwent genetic screening for ACE polymorphisms.
\end{abstract}

\section{Introduction}

The insertion (I)/deletion (D) polymorphism of ACE was previously described in association with adult respiratory distress syndrome and correlated with poor outcome [1]. Several studies showed that SARS-COV2 induces lung damage by increasing the permeability of the alveolar-capillary barrier leading to ARDS [2]. ACE is a metallopeptidase that converts angiotensin I to angiotensin II (Ang II), acting as a vasoconstrictor, and it also degrades bradykinin, acting as a vasodilator. ACE2 is a distinct type but a close homologue of ACE; it was identified as aco-receptor for coronaviruses on epithelial lung cells [3]. ACE2 inactivates Ang II and is a negative regulator of the system thus down-regulates the rennin angiotensin system. In a small cohort study, Ang II was remarkably increased in COVID-19 plasma samples [4]. Previous studies reported high Ang II levels in SARS infected mice; in this case Ang II was related to severity of disease, whereas the mice deficient for ACE showed milder disease [5].

\section{Material and methods}

We examined 26 patients affected by severe COVID-19, admitted in our intensive care unit between 16 March 2020 and 15 april 2020. 21 were males and 9 females, with mean age $58.5 \pm 10.5$. At admission, 24 patients had severe respiratory failure with $\mathrm{paO} 2 / \mathrm{FiO} 2<100 \mathrm{mmHg}$ and were treated with mechanical ventilation; 2 patients had mild to moderate respiratory failure with $\mathrm{paO} 2 / \mathrm{FiO} 2>200 \mathrm{mmHg}$.

The baseline characteristics of patients are described in Table 1. 17 patients $(65 \%)$ were affected by hypertension. Mean BMI was $28.5 \pm 4.5$. We tested all patients to assess mutational status of the ACE encoding gene by real time polymerase chain reaction amplification (Table 2).

\section{Results and discussion}

26 patients underwent genetics testing. We found that $19(73 \%)$ of our critically ill patients had the D/D polymorphism, 6 (23\%) presented I/D polymorphism and only 2 patients ( $8 \%$ ) I/I polymorphism.

Delanghe et al. recently observed that the prevalence of COVID-19 significantly correlated with ACE D/I polymorphism in 33 countries. At the same time, other polymorphisms, such as complement C3, haptoglobin and vitamin $\mathrm{D}$ binding protein, did not show a significant
Table 1. Baseline Characteristics of critically ill COVID 19 patients

\begin{tabular}{|c|c|}
\hline Age (mean \pm DS) & $58.5 \pm 10.5$ \\
\hline Male sex $n(\%)$ & $21 / 26(81 \%)$ \\
\hline BMI (mean \pm DS) & $28.5 \pm 4.5$ \\
\hline Hypertension $n(\%)$ & $17 / 26(65 \%)$ \\
\hline Diabetes $n(\%)$ & $4 / 26(15 \%)$ \\
\hline Mortality $n(\%)$ & $4(15 \%)$ \\
\hline Pulmonary Embolism $n(\%)$ & $14 / 26(54 \%)$ \\
\hline
\end{tabular}

Table 2. paO2/FiO2 at admission for different ACE polymorphysms. ACE: Gene coding for angiotensin-converting enzyme

\begin{tabular}{|c|c|c|}
\hline & Patients n/\% & paO2/FiO2 $\mathbf{~ m m H g}$ \\
\hline ACE DD & $19(73 \%)$ & $75,6+/-11,3$ \\
\hline ACE ID & $6(23 \%)$ & $86,9+/-15,3$ \\
\hline ACE II & $2(8 \%)$ & $>200$ \\
\hline
\end{tabular}

correlation with COVID-19 prevalence [6]. Different studies have associated the $\mathrm{D} / \mathrm{D}$ genotype with an increased risk of cardiovascular pathologies, due to a consequent increase in the plasma levels of ACE compared to subjects with genotype I/I [7].

There is substantial evidence that the ACE I/D polymorphism determines plasmatic ACE concentration, being approximately doubled in individuals with the DD genotype compared to II individuals, with ID individuals having intermediate concentrations. In a recent study, the ACE DD and ID polymorphisms were found to be significantly associated with smoking habits, high plasma ACE levels and high IL-6 levels in STEMI patients [8].

A metanalysis suggests that ACE polymorphisms, particularly the homozygote variant (DD), might contribute to the risk of respiratory disease with pulmonary hypertension [9].

*Correspondence to: Anna Annunziata, MD, Department of Respiratory Pathophysiology Monaldi - Cotugno Hospital, Naples, Italy, E-mail: anna. annunziata@gmail.com

Key words: ACE polymorphism, insertion, deletion, COVID 19, ARDS

Received: May 09, 2020; Accepted: May 26, 2020; Published: May 29, 2020 
In several studies, the association between different genes, and not a single one, provide a higher or lower risk of disease, not a single gene [10]. ACE gene I/D polymorphism has also been previously studied in relation to the susceptibility to different diseases with contrasting results. Some authors had described a correlation between ACE polymorphism prevalence and progression of SARS [11]. As the ACE I/D genotype might be involved in the pathogenesis of COVID-19 infection, further studies are required to assess the clinical outcomes of COVID-19 infection in ACE D/D, I/D and I/I carriers and to study the exact role of the ACE polymorphism in COVID-19 infection and its interaction with other polymorphisms.

As literature data are lacking in this scenario, our observation is only preliminary because of the relatively small size of our sample. Further studies should be performed involving a bigger cohort and a control group to better understand the relationship between severity of COVID-19 and different genotypes.

\section{References}

1. Marshall RP, Webb S, Bellingan GJ, Montgomery HE, Chaudhari B, et al. (2002) Laurent, Angiotensin converting enzyme insertion/deletion polymorphism is associated with susceptibility and outcome in acute respiratory distress syndrome. Am J Respir Crit Care Med 166: 646-650. [Crossref]

2. Gattinoni L, Chiumello D, Rossi S (2020) COVID-19 pneumonia: ARDS or not? Critical Care 24: 154. [Crossref]
3. Kuba K, Imai Y, Penninger JM (2006) Angiotensin-converting enzyme 2 in lung diseases. Curr Opin Pharmacol 6: 271-276. [Crossref]

4. Liu Y, Yang Y, Zhang C, Huang F, Wang F, et al. (2020) Clinical and biochemical indexes from 2019-nCoV infected patients linked to viral loads and lung injury. Sci China Life Sci 63: 364-374. [Crossref]

5. Imai Y, Kuba K, Rao S, Huan Y, Guo F, et al. (2005) Angiotensin-converting enzyme 2 protects from severe acute lung failure. Nature 436: 112-116. [Crossref]

6. Delanghe JR, Speeckaert MM, De BuyzereML (2020) COVID-19 infections are also affected by human ACE1 D/I polymorphism. Clinical Chemistry and Laboratory Medicine. [Crossref]

7. Ruggenenti P, Bettinaglio P, Pinares F, Remuzzi G (2008) Angiotensin converting enzyme insertion/deletion polymorphism and renoprotection in diabetic and nondiabetic nephropathies. Clin J Am Soc Nephrol 3: 1511-1525. [Crossref]

8. Dai S, Ding M, Liang N, Li Z, Li D, et al. (2019) Associations of ACE I/D polymorphism with the levels of ACE, kallikrein, angiotensin II and interleukin-6 in STEMI patients. Sci Rep 9: 19719.

9. Ma Y, Tong X, Liu Y, Liu S, Xiong H, et al. (2018) ACE gene polymorphism is associated with COPD and COPD with pulmonary hypertension: a meta-analysis. Int $J$ Chron Obstruct Pulmon Dis 13: 2435-2446. [Crossref]

10. Gungor (2011) The presence of PAI-1 4G/5G and ACE DD genotypes increases the risk of early stage AVF thrombosis in hemodialysis patients. Ren Fail 33: 169-175.

11. Itoyama S, Keicho N, Quy T, Phi NC, Long HT, et al. (2004) ACE1 polymorphism and progression of SARS, Biochem Biophys Res Commun 323: 1124-1129. [Crossref]

Copyright: (C2020 Annunziata A. This is an open-access article distributed under the terms of the Creative Commons Attribution License, which permits unrestricted use, distribution, and reproduction in any medium, provided the original author and source are credited. 